\title{
Erratum to: Technical Specifications of Medical Imaging Equipment
}

Kwan Hoong Ng, Jeannie Hsiu Ding Wong and Sock Keow Tan

\section{Erratum to:}

Chapter 4 in: C. Borrás (ed.), Defining the Medical

Imaging Requirements for a Rural Health Center,

DOI 10.1007/978-981-10-1613-4_4

The original version of Chapter 4 was inadvertently published with incorrect author name "Kwan Hong Ng" instead of "Kwan Hoong Ng". The erratum chapter and the book have been updated with the changes.

The updated original online version for this chapter can be found at DOI 10.1007/978-981-10-1613-4_4

\footnotetext{
K.H. Ng ( $₫) \cdot$ J.H.D. Wong $(\bowtie) \cdot$ S.K. Tan

Department of Biomedical Imaging, University of Malaya, Kuala Lumpur, Malaysia e-mail:ngkh@ummc.edu.my

J.H.D. Wong

e-mail: jeannie_wong80@um.edu.my

S.K. Tan

e-mail: fionetsk@gmail.com 